\title{
Mecanismos de promoção, proteção e apoio ao aleitamento materno no Brasil
}

\author{
Mechanisms to promote, protection and support to breastfeeding in Brazil \\ Mecanismos para la promoción, protección y apoio a la lactancia materna en Brazil
}

\begin{abstract}
RESUMO
Objetivo: Analisar os marcos políticos, jurídico-legais e sociais que contribuíram para a instituição da prática do aleitamento materno (AM) no Brasil. Métodos: Trata-se de revisão integrativa de literatura, realizada nas bases de dados LILACS, Google Scholar, Medline e SciELO, utilizando-se os descritores: Aleitamento Materno, Atenção Primária em Saúde e Políticas Públicas, integrados com o operador booleano AND. A busca resultou em 15 estudos, publicados entre 1999 e 2020. Resultados: Foi possível verificar que, impulsionado por iniciativas internacionais, o Brasil vem implantando políticas públicas de incentivo ao AM em âmbito nacional, a exemplo do Programa Nacional de Aleitamento Materno e dos Bancos de Leite Humano. Tais ações impactaram positivamente nos indicadores de saúde da população, contudo necessitam de suporte jurídico legal para assegurar a aplicabilidade, pois envolvem diversos setores da sociedade. Conclusão: As medidas implementadas historicamente permitiram a expansão da prática do AM e indicam interesse governamental de apoio ao tema.
\end{abstract}

DESCRITORES: Aleitamento Materno; Atenção Primária em Saúde; Políticas Públicas.

\section{ABSTRACT}

Objective: To analyze the political, legal and social frameworks that contributed to the institution of breastfeeding (BF) in Brazil. Methods: It is an integrative review, carried out in LILACS, Google Scholar, MEDLINE and SciELO, using the descriptors: Breastfeeding, Primary Health Care and Public Policies, with the Boolean operator AND. The search resulted in 15 studies, published between 1999 and 2020. Results: It was possible to verify that, driven by international initiatives, Brazil has been implementing public policies that encourage BF nationwide, such as the National Breastfeeding Program and Human Milk Banks. Such actions had a positive impact on the population's health indicators, however, they need legal support to ensure applicability, because they involve different sectors of society. Conclusion: The measures historically implemented have allowed for the expansive of the practice of BF.

ESCRIPTORS: Breastfeeding; Primary Health Care; Public Policies.

\section{RESUMEN}

Objetivo: Analizar los marcos políticos, legales y sociales que contribuyeron a la institución de la lactancia materna (LM) en Brasil. Método: Es una revisión integradora de la literatura, utilizando las bases de dados LILACS, Google Scholar, Medline y SciELO, con los descriptores: Lactancia Materna, Atención Primaria de Salud y Políticas Públicas, con el operador booleano AND. La búsqueda resultó en 15 estudios, publicados entre 1999 y 2020. Resultados: Se pudo constatar que, impulsado por iniciativas internacionales, Brasil viene implementando políticas públicas que incentivan LM a nivel nacional, como el Programa Nacionalde Lactancia Materna y los Bancos de Leche Materna. Tales acciones tuvieron un impacto positivo en los indicadores de salud de la población, sin embargo, necesitan apoyo legal para garantizar la aplicabilidad, porque involucran a diferentes sectores de la sociedad. Conclusión: Las medidas implementadas historicamente permitieron la expansión de la práctica de LM.

DESCRIPTORES: Lactancia Materna; Atención Primaria de Salud; Políticas Públicas.

RECEBIDO EM: 28/09/2020 APROVADO EM: 23/10/2020

\section{Thiana Pinho Araújo}

Nutricionista. Especialista em Nutrição Clínica: Metabolismo, Prática e Terapia Nutricional. Mestranda do Programa de Pós-Graduação Saúde, Ambiente e Sociedade na Amazônia do Instituto de Ciências da Saúde da Universidade Federal do Pará (ICS/UFPA). ORCID: 0000-0001-9384-8084 


\section{Lucrecia Aline Cabral Formigosa}

Enfermeira. Especialista em Saúde Coletiva. Mestranda do Programa de Pós-Graduação Saúde, Ambiente e Sociedade na Amazônia do Instituto de Ciências da Saúde da Universidade Federal do Pará (ICS/UFPA).

ORCID: 0000-0003-4245-672X

\section{Adrianne Pureza Maciel}

Nutricionista. Especialista em Saúde do Idoso e em Nutrição Clínica: Metabolismo, Prática e Terapia Nutricional. Nutricionista do Restaurante Universitário da Universidade Federal do Pará (RU/UFPA).

ORCID: 0000-0001-5546-2331

\section{Naíza Nayla Bandeira de Sá}

Nutricionista. Doutora em Ciências da Saúde pela Universidade de Brasília. Docente do Programa de Pós-Graduação em Saúde, Ambiente e Sociedade na Amazônia do Instituto de Ciências da Saúde da Universidade Federal do Pará (ICS/UFPA).

ORCID: 0000-0002-1267-1624

\section{INTRODUÇÃO}

0 s primeiros anos de vida de uma criança são marcados pela rapidez no crescimento e desenvolvimento. Para que tais fenômenos ocorram adequadamente, é indispensável o papel da alimentação adequada. A qualidade e a quantidade dos alimentos consumidos nesta fase têm repercussões ao longo da vida, associando-se ao perfil de saúde ${ }^{1}$.

A Organização Mundial da Saúde (OMS) recomenda que o único alimento ofertado nos 06 primeiros meses de vida seja o leite materno (LM), diretamente da mama ou extraído, com a possibilidade do uso de algum suplemento medicamentoso. A partir desse período, deve-se iniciar a alimentação complementar (AC), dando preferência aos alimentos saudáveis e a oferta de refeições equilibradas em macro e micronutrientes ${ }^{2}$.

O cumprimento de tais recomendações impactam diretamente na melhoria de indicadores de saúde, a exemplo da redução da taxa de mortalidade infantil, evitando até $13 \%$ dos óbitos ocasionados por doenças preveníveis em crianças menores de 5 anos em todo o mundo, além de salvar 1,47 milhões de vidas por ano nos países em desenvolvimento ${ }^{3}$. Entre as lactantes, estima-se que o ato de amamentar pode prevenir 98.243 mortes causadas por câncer de mama e ovário, assim como de diabetes tipo II, ao ano. Esses números se traduzem em um custo global de US\$ 1,1 bilhão para tratamentos de saúde ${ }^{4}$.

Ao longo do tempo, inúmeros esforços dos movimentos políticos e sociais em favor do AM resultaram na expansão da prática do AME em crianças de 0 a 06 meses de idade, bem como o aumento da duração mediana do AM, demonstrando que mães, quando corretamente orientadas, tendem a amamentar de forma mais segura e por mais tempo ${ }^{5,6}$.

Não obstante ainda prevalece a baixa adesão a nível regional, nacional e mundial, apesar dos estudos evidenciarem a importância do aleitamento materno (AM) para o binômio mãe-filho e da implementação de ações de promoção, proteção e apoio à prática ${ }^{7}$, pois as intervenções voltadas a prática, sobretudo na sua forma exclusiva, são extremamente complexas, requerendo envolvimento de diversas áreas como educação, desenvolvimento social, direitos entre outras ${ }^{3}$.

A partir dessa perspectiva, surgiu o seguinte questionamento: quais os mecanismos de promoção, proteção e apoio ao AM utilizados no Brasil? Assim, este trabalho buscou analisar os marcos políticos, jurídico-legais e sociais que contribuíram para a instituição e fortalecimento da prática do AM no Brasil.

\section{MÉTODO}

Para alcançar o objetivo proposto, foi realizado um estudo descritivo, pesquisa bibliográfica do tipo revisão integrativa de literatura, elaborada de acordo com as etapas:1) identificação do tema e questão norteadora; 2) definição de critérios de inclusão e exclusão de estudos/amostragem e busca na literatura; 3) definição das informações a serem extraídas dos estudos selecionados/ categorização dos estudos; 4) avaliação dos estudos incluídos na revisão integrativa; 5) interpretação dos resultados e (6) apresentação da síntese do conhecimento ${ }^{8}$.

O levantamento de artigos foi realizado nas bases de dados eletrônicas: Medical Literature Analysis and Retrieval System Online (MEDLINE), Literatura Latino-americana e do Caribe em Ciências da Saúde (LILACS), Google Scholar e Scientific Electronic Library Online (SciELO). Utilizaram-se como termos de busca os descritores em saúde (DECS): Aleitamento Materno, Atenção Primária em Saúde e Políticas Públicas, juntamente com o operador booleano AND.

Utilizaram-se como critérios de inclusão: título e/ou resumo que indicassem tratar da temática do AM, especialmente quanto aos marcos políticos, jurídico-legais e sociais, publicados nos idiomas inglês, português e espanhol, no período de 1999 a 2020. Excluíram-se aqueles duplicados ou que não correspondessem ao objetivo proposto.

A etapa de seleção dos artigos ocorreu entre os meses de julho e agosto de 2020, norteado pelo instrumento de URSI, o qual foi adaptado para a pesquisa, contendo as variáveis: título, ano, objetivo e principais resultados, apresentado no Quadro 1.

A avaliação dos estudos quanto à observância dos critérios de elegibilidade ocorreu após a leitura minuciosa de todos os títulos e resumos identificados em cada base de dados, por dois avaliadores separadamente, e, em caso de discordância, foi consultado um terceiro autor. Em seguida, para a análise descritiva, procedeu-se 
a leitura na íntegra dos estudos incluídos, cujos resultados foram reunidos por semelhança de conteúdo, considerando o marco histórico e sua evolução cronológica.

\section{RESULTADOS}

Após a aplicação dos critérios de elegibilidade, foram selecionados 15 estu- dos para compor esta revisão integrativa, cujas principais informações dos artigos foram organizadas um quadro sinóptico (Quadro 1).

Quadro1: Descrição dos artigos selecionados na revisão integrativa

\begin{tabular}{|c|c|c|c|}
\hline TÍTULO & ANO & OBJETIVO & PRINCIPAIS RESULTADOS \\
\hline $\begin{array}{l}\text { Reflexões sobre a } \\
\text { amamentação no } \\
\text { Brasil: de como pas- } \\
\text { samos a } 10 \text { meses de } \\
\text { duração9. }\end{array}$ & 2003 & $\begin{array}{l}\text { Rever a trajetória do programa nacional } \\
\text { privilegiando a análise da influência das } \\
\text { políticas internacionais e analisando-o } \\
\text { em quatro períodos: } 1975 \text { a 1981, } 1981 \\
\text { a 1986, } 1986 \text { a } 1996 \text { e de } 1996 \text { a } 2002 .\end{array}$ & $\begin{array}{l}\text { Levando-se em conta os acertos e erros do programa nos } \\
\text { anos anteriores, e a necessidade de melhorar os índices de } \\
\text { amamentação no país, a proposta do Ministério da Saúde } \\
\text { é continuar a centrar as atividades naquelas já delineadas } \\
\text { anteriormente, redirecionar o trabalho intensificando a } \\
\text { atenção humanizada ao recém-nascido. }\end{array}$ \\
\hline $\begin{array}{l}\text { Biopolíticas do } \\
\text { aleitamento materno: } \\
\text { uma análise dos } \\
\text { movimentos global } \\
\text { e local e suas } \\
\text { articulações com } \\
\text { os discursos do } \\
\text { desenvolvimento } \\
\text { social }{ }^{10}\end{array}$ & 2018 & $\begin{array}{l}\text { Analisar as articulações entre } \\
\text { a produção das biopolíticas de } \\
\text { amamentação e os discursos } \\
\text { produzidos sobre desenvolvimento } \\
\text { social após o período pós-guerra } \\
\text { com vistas à problematização } \\
\text { da dicotomia natureza/ cultura } \\
\text { mediante a qual a amamentação é } \\
\text { frequentemente operada. }\end{array}$ & $\begin{array}{l}\text { Os discursos desenvolvimentistas atuam como } \\
\text { uma referência sociocultural com base na qual a } \\
\text { amamentação é operada, o que permite dizer que } \\
\text { a amamentação é uma prática tão natural quanto } \\
\text { política, econômica e social. }\end{array}$ \\
\hline $\begin{array}{l}\text { História do alojamento } \\
\text { conjunto }{ }^{11}\end{array}$ & 1999 & $\begin{array}{l}\text { Fazer uma revisão sobre a trajetória } \\
\text { do alojamento conjunto mãe-filho e } \\
\text { as transformações no atendimento } \\
\text { perinatal influenciadas pelos avanços } \\
\text { da medicina. }\end{array}$ & $\begin{array}{l}\text { Uma das formas encontradas para superar separação } \\
\text { mãe-filho foi a criação do alojamento conjunto que permitia } \\
\text { a ambos permanecer juntos desde o nascimento até a } \\
\text { alta. Essa experiência tinha a intenção de devolver à mãe a } \\
\text { possibilidade de cuidar do próprio filho, mas o projeto extin- } \\
\text { guiu-se e só foi ressuscitado na década de } 70 \text { com o apoio } \\
\text { de organizações internacionais respeitadas. }\end{array}$ \\
\hline $\begin{array}{l}\text { Conjunto de medidas } \\
\text { para o incentivo do } \\
\text { aleitamento materno } \\
\text { exclusivo intra-hos- } \\
\text { pitalar: evidências de } \\
\text { revisões sistemáticas }\end{array}$ & 2018 & $\begin{array}{l}\text { Identificar as principais recomendações } \\
\text { encontradas em revisões sistemáticas } \\
\text { relacionadas aos fatores de proteção } \\
\text { do aleitamento materno exclusivo } \\
\text { intra-hospitalar. }\end{array}$ & $\begin{array}{c}\text { As principais recomendações foram: o contato pele a pele } \\
\text { precoce; a permanência da criança em alojamento conjunto; } \\
\text { a intervenção na dor mamilar durante a amamentação; } \\
\text { a restrição do uso de suplementação para lactentes; o } \\
\text { aleitamento materno sob livre demanda; e as intervenções } \\
\text { educativas por meio de suporte individual e/ou em grupos } \\
\text { durante a internação }\end{array}$ \\
\hline $\begin{array}{l}\text { Representações sociais } \\
\text { de doadoras sobre a } \\
\text { doaçãão de leite hu- } \\
\text { mano em um hospital } \\
\text { universitário }\end{array}$ & 2020 & $\begin{array}{c}\text { Conhecer as representações sociais de } \\
\text { doadoras sobre a doação de leite huma- } \\
\text { no em um hospital universitário. }\end{array}$ & $\begin{array}{l}\text { Os temas relacionados à doação que emergiram das falas } \\
\text { dessas doadoras foram: banco de leite humano: lugar de } \\
\text { acolhimento e aprendizagem; doar o leite materno: dá } \\
\text { trabalho e exige compromisso e ser doadora é compartilhar } \\
\text { o que tem e ajudar a quem precisa. }\end{array}$ \\
\hline $\begin{array}{l}\text { Acompanhamento dos } \\
\text { atendimentos de puér- } \\
\text { peras e recém-nasci- } \\
\text { dos em um Banco de } \\
\text { Leite Humano }{ }^{14}\end{array}$ & 2020 & $\begin{array}{l}\text { Avaliar a associação entre as carac- } \\
\text { terísticas maternas e o acompanha- } \\
\text { mento dos atendimentos no Banco de } \\
\text { Leite Humano (BLH) à puérpera e ao } \\
\text { recém-nascido internado. }\end{array}$ & $\begin{array}{l}\text { Os motivos principais para encaminhamento ao BLH foram } \\
\text { perda de peso do recém-nascido e dificuldade na pega. } \\
\text { Foram encontradas associações estatisticamente significa- } \\
\text { tivas entre o acompanhamento do banco de leite humano e } \\
\text { as variáveis idade materna. }\end{array}$ \\
\hline $\begin{array}{l}\text { Promoção comercial } \\
\text { ilegal de produtos que } \\
\text { competem com o alei- } \\
\text { tamento materno }{ }^{15}\end{array}$ & 2020 & $\begin{array}{l}\text { Avaliar se a comercialização de fór- } \\
\text { mulas infantis, mamadeiras, bicos, } \\
\text { chupetas e protetores de mamilo é } \\
\text { realizada em cumprimento com a } \\
\text { Norma Brasileira de Comercialização } \\
\text { de Alimentos para Lactentes e Crianças } \\
\text { de Primeira Infância e de Produtos de } \\
\text { Puericultura Correlatos (NBCAL). }\end{array}$ & $\begin{array}{l}\text { Mais de um quinto dos estabelecimentos comerciais faziam } \\
\text { promoção comercial de fórmulas infantis para lactentes, } \\
\text { mamadeiras e bicos, apesar de essa prática ser proibida no } \\
\text { Brasil há trinta anos. }\end{array}$ \\
\hline
\end{tabular}




\section{artigo}

\begin{tabular}{|c|c|c|c|}
\hline $\begin{array}{l}\text { Compliance of infant } \\
\text { formula promotion on } \\
\text { websites of Brazilian } \\
\text { manufacturers and } \\
\text { drugstores }^{16}\end{array}$ & 2020 & $\begin{array}{l}\text { Verificar o cumprimento da Lei } n^{\circ} \\
11.265 / 2006 \text { nas estratégias de pro- } \\
\text { moção para fórmula infantil em sites } \\
\text { brasileiros de fabricantes e redes de } \\
\text { farmácias. }\end{array}$ & $\begin{array}{l}\text { Foram identificados descumprimentos da Lei } n^{\circ} \\
11.256 / 2006 \text { em quase todos sites de fabricantes de } \\
\text { fórmulas infantis e em todos os sites de redes de farmácias. } \\
\text { A maioria das estratégias de promoção foram encontradas } \\
\text { em sites de farmácias, principais canais de vendas online. }\end{array}$ \\
\hline $\begin{array}{l}\text { Licença-maternidade } \\
\text { e aleitamento materno } \\
\text { exclusivo }^{17}\end{array}$ & 2019 & $\begin{array}{l}\text { Analisar a associação entre licença- } \\
\text {-maternidade e aleitamento materno } \\
\text { exclusivo (AME) e estimar a prevalência } \\
\text { de AME em crianças menores de seis } \\
\text { meses de vida. }\end{array}$ & $\begin{array}{l}\text { A licença-maternidade contribuiu para a prática do AME } \\
\text { em crianças menores de seis meses de vida, o que indica } \\
\text { a importância desse benefício na proteção da prática para } \\
\text { mulheres inseridas no mercado de trabalho formal. }\end{array}$ \\
\hline $\begin{array}{l}\text { Determinantes do } \\
\text { aleitamento materno } \\
\text { exclusivo em lacten- } \\
\text { tes menores de seis } \\
\text { meses nascidos com } \\
\text { baixo peso }\end{array}$ & 2019 & $\begin{array}{l}\text { Avaliar os fatores associados ao (AME) } \\
\text { em lactentes com baixo peso ao nascer, } \\
\text { menores de seis meses e residentes em } \\
64 \text { municípios brasileiros. }\end{array}$ & $\begin{array}{l}\text { O AME foi mais prevalente entre lactentes com baixo } \\
\text { peso ao nascer cujas mães tinham de } 20-35 \text { anos, não } \\
\text { trabalhavam fora ou estavam em licença maternidade; } \\
\text { nos que nasceram em Hospital Amigo da Criança e que } \\
\text { residiam em municípios com maior número de BLH por } 10 \\
\text { mil nascidos vivos. }\end{array}$ \\
\hline $\begin{array}{l}\text { Iniciativa Hospital } \\
\text { Amigo da Criança: } 25 \\
\text { anos de experiência } \\
\text { no Brasil }^{19}\end{array}$ & 2019 & $\begin{array}{l}\text { Descrever a experiência de } 25 \text { anos da } \\
\text { Iniciativa Hospital Amigo da Criança } \\
\text { (IHAC) no Brasil. }\end{array}$ & $\begin{array}{l}\text { Hospitais credenciados como o Hospital Amigo da Criança } \\
\text { mostram índices de amamentação superiores ao de hos- } \\
\text { pitais não credenciados, entretanto o número de hospitais } \\
\text { credenciados no Brasil ainda é pouco se comparado com } \\
\text { outros países. }\end{array}$ \\
\hline $\begin{array}{l}\text { Práticas educativas } \\
\text { segundo os "Dez pas- } \\
\text { sos para o sucesso do } \\
\text { aleitamento materno" } \\
\text { em um Banco de Leite } \\
\text { Humano }^{20}\end{array}$ & 2017 & $\begin{array}{l}\text { Avaliar práticas educativas segundo } \\
\text { os "Dez Passos para o Sucesso do } \\
\text { Aleitamento Materno" em Banco de } \\
\text { Leite Humano. }\end{array}$ & $\begin{array}{l}\text { As orientações recebidas sobre amamentação no pré-natal } \\
\text { (passo 3) prevaleceram entre mães de 30-39 anos e o con- } \\
\text { tato pele/pele (passo 4) entre as orientadas. } 0 \text { treinamento } \\
\text { sobre amamentação (passo 5) predominou entre aquelas } \\
\text { que amamentaram exclusivamente. Notou-se maior } \\
\text { prevalência de amamentação exclusiva (passo 6) e sob livre } \\
\text { demanda (passo 8) e uso de bicos artificiais (passo 9) entre } \\
\text { os lactentes de mães orientadas. }\end{array}$ \\
\hline $\begin{array}{l}\text { Duração do aleita- } \\
\text { mento materno e sua } \\
\text { associação com ca- } \\
\text { racterísticas maternas } \\
\text { e orientações sobre } \\
\text { incentivo à amamen- } \\
\text { tação recebidas no } \\
\text { pré-natal em unidades } \\
\text { básicas de Saúde } \\
\text { da Família de um } \\
\text { município do Nordeste } \\
\text { Brasileiro }\end{array}$ & 2019 & $\begin{array}{l}\text { Estimar o tempo de aleitamento ma- } \\
\text { terno entre crianças atendidas na rede } \\
\text { pública de saúde e verificar diferenças } \\
\text { segundo características maternas e da } \\
\text { atenção pré-natal (número de consultas } \\
\text { e orientações profissionais). }\end{array}$ & $\begin{array}{c}\text { As estimativas destacam tempos de aleitamento materno } \\
\text { exclusivo e total aquém do esperado, sendo a duração } \\
\text { influenciada por características maternas e pela adequação } \\
\text { do pré-natal no número de consultas e nas orientações } \\
\text { sobre amamentaçãa }\end{array}$ \\
\hline $\begin{array}{l}\text { Associação entre o } \\
\text { grau de implantação } \\
\text { da Rede Amamenta } \\
\text { Brasil e indicadores de } \\
\text { amamentação } 22\end{array}$ & 2016 & $\begin{array}{c}\text { Avaliar a implantação da Rede Amamen- } \\
\text { ta Brasil e seu impacto sobre indicadores } \\
\text { de aleitamento materno (AM) }\end{array}$ & $\begin{array}{l}\text { Dificuldades para a implantação da Rede Amamenta Brasil } \\
\text { foram identificadas, e os indicadores de AM variaram de } \\
\text { acordo com o número de critérios de certificação cumpridos } \\
\text { pelas UBS. }\end{array}$ \\
\hline $\begin{array}{l}\text { Why invest in early } \\
\text { childhood??23 }\end{array}$ & 2020 & $\begin{array}{l}\text { Descrever a importância de políticas } \\
\text { públicas voltadas à primeira infância. }\end{array}$ & $\begin{array}{l}\text { Dados apontam que o investimento nos primeiros } 1000 \\
\text { dias de vida ajuda a combater a pobreza e as desigualdades } \\
\text { sociais e de programas e iniciativas que têm sido adotadas } \\
\text { nacional e mundialmente }\end{array}$ \\
\hline
\end{tabular}

\section{DISCUSSÃO}

O panorama brasileiro do AM em décadas passadas era marcado pela baixa adesão à prática, com mediana de 2,5 meses de duração, aliado ao incentivo por parte de profissionais médicos ao consumo de fórmulas infantis, amplificado pela massiva propaganda antiética e venda desses produtos; o leite em pó tam- 
bém era distribuído em unidades de saúde e hospitais pelo Governo através dos Programas de Suplementação Alimentar da época9.

Diante das altas taxas de mortalidade infantil em todo o mundo, sobretudo nos países em desenvolvimento, ganharam força os movimentos em favor da amamentação, que passam a empreender várias ações de fomento.

Pontuam-se, a seguir, alguns dos marcos nacionais pró-amamentação (Figura 1):

Em 1979, reunião conjunta entre a Organização Mundial da Saúde (OMS) e o Fundo das Nações Unidas para a Infância (UNI$\mathrm{CEF)}$ resultou na aprovação do Código Internacional de Comercialização de Substitutos do Leite Materno 3 . O Brasil participou representado pela presidência do Instituto Nacional de Alimentação e Nutrição (INAN), fato que impulsionou a discussão no país?

Dessa forma, no ano de 1981, o INAN instituiu a Política Nacional de Incentivo ao Aleitamento Materno (PNIAM), a qual obteve visibilidade em âmbito internacional, pela diversidade de ações propostas em favor
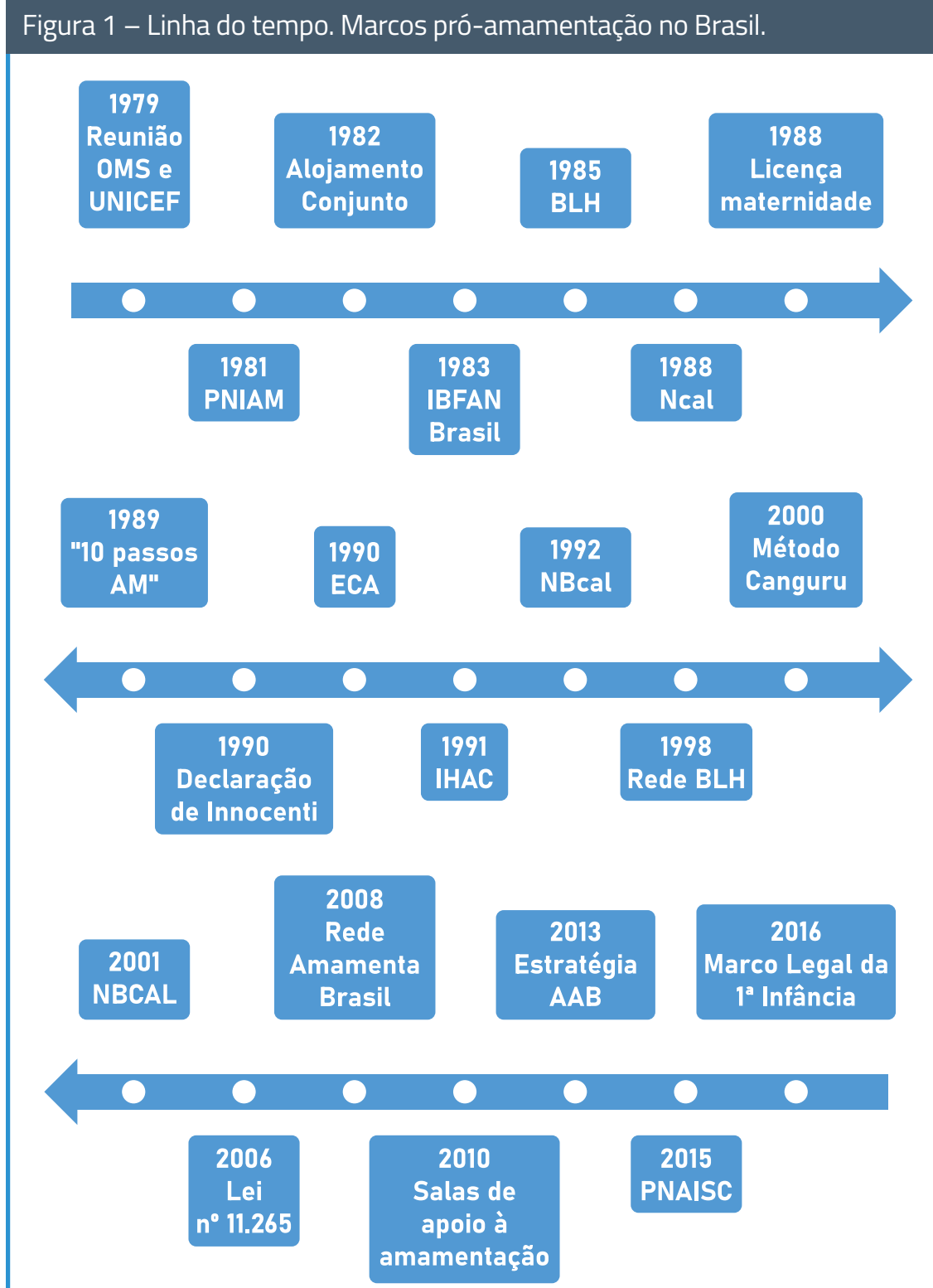

Fonte: Adaptado de Ministério da Saúde, $2017^{3}$.

da promoção, proteção e apoio ao AM, dentre elas a divulgação de campanhas através dos meios de comunicação ${ }^{10}$, bem como a criação de leis reguladoras do marketing e da venda de leites artificiais, além do incentivo à implantação do alojamento conjunto (AC), entendido como a permanência do bebê junto à mãe por tempo integral, em maternidades ${ }^{3}$.

A partir de 1982, todas as unidades hospitalares do país foram orientadas a instituir o AC, tendo como base as diretivas do I Encontro Sobre Alojamento Conjunto, sendo, no ano seguinte, definidas as primeiras normas básicas de organização e funcionamento do sistema, o qual passou a abranger os hospitais universitários em 1987. A prática, que foi contemplada e considerada obrigatória pelo Estatuto da Criança e do Adolescente (ECA), teve a sua regulamentação garantida por meio da Portaria $n^{\circ} 1.016 / 2003^{11,12}$.

Outro elemento essencial do movimento em favor do AM, o Banco de Leite Humano (BLH), é responsável pela coleta e oferta de leite humano pasteurizado a recém-nascidos internados em condições específicas, como prematuridade e muito baixo peso, sendo o primeiro implantado ainda em 1943, na cidade do Rio de Janeiro, pelo Instituto Fernandes Figueira, e considerado como referência até os dias atuais ${ }^{13}$.

Com a criação da PNIAM, o serviço assumiu papel mais abrangente e, em 1985, teve seu modelo operacional revisado, tornando-se base para a expansão do sistema no país14. Buscando promover o compartilhamento de conhecimentos entre os BLH instituídos, o Ministério da Saúde (MS) criou, no ano de 1998, a Rede Nacional de Bancos de Leite Humano - r-BLH-BR ${ }^{10}$.

Décadas antes do aquecimento da discussão global em torno da associação negativa entre a baixa adesão ao $\mathrm{AM} \mathrm{e} \mathrm{a} \mathrm{alta} \mathrm{taxa} \mathrm{de}$ mortalidade infantil, já despontavam alertas de instituiçôes como o Rotary Clube e de médicos que atuavam em áreas mais pobres do Brasil quanto aos malefícios da intensa promoção de substitutos do leite materno ${ }^{10}$.

Nesse contexto, o país adaptou o "Código Internacional" aprovado no ano de 1979, e, em 1988, o Conselho Nacional de Saúde instituiu as "Normas para Comercialização de Alimentos para Lactentes (Ncal)", proibindo tanto a divulgação quanto a promoção 
comercial de fórmulas infantis ${ }^{15}$. Nas décadas seguintes, a Ncal passou por revisões que ampliaram seu escopo e determinaram novas regras de rotulagem e fiscalização, buscando acompanhar as diversas estratégias de marketing praticadas pela indústria ${ }^{3}$.

Com a publicação da Lei no ${ }^{\circ} 11.265 / 2006$ e posterior regulamentação pelo Decreto $n^{\circ}$ $8.552 / 2015$, a diretriz - que passou a ser intitulada "Norma Brasileira de Comercialização de Alimentos para Lactentes e Crianças de Primeira Infância e de Produtos de Puericultura Correlatos (NBCAL)" - ganhou ainda mais força enquanto dispositivo fundamental para a proteção do AM, tendo como objetivo a normatização do comércio de alimentos para crianças menores de 03 anos, bem como de produtos como bicos, chupetas, mamadeiras e protetores de mamilo ${ }^{15}$.

Parceira do movimento em favor da saúde de bebês e crianças pequenas por meio da promoção e proteção da amamentação, a Rede Internacional em Defesa do Direito de Amamentar (IBFAN) foi criada no final dos anos 70 , sendo instituída no Brasil na década de 1980. Nesse sentindo, a rede constituiu-se em oposição à propaganda antiética de produtos que prejudicam a prática do $\mathrm{AM}$, sobretudo aqueles abarcados pela NBCAL, realizando monitoramento contínuo e cobrando mais engajamento de atores importantes como a indústria e empresas do ramo, bem como de profissionais da área da saúde ${ }^{16}$.

Em consonância com os diversos esforços empregados, benefícios em favor do AM, como a garantia de licença-maternidade por 120 dias para as mulheres trabalhadoras, licença-paternidade, assim como o direito às puérperas privadas de liberdade de permanecer com os filhos durante o período de amamentação, foram assegurados a partir da promulgação da Constituição Federal ${ }^{3}$.

A ampliação da licença-maternidade para 180 dias, período recomendado pela OMS a fim de garantir o aleitamento materno exclusivo (AME), é realidade, mas inclui apenas mulheres trabalhadoras formais, por meio do Programa Empresa Cidadã, aprovada em 2010 pelo Congresso Nacional. Entretanto, a concessão do benefício depende da adesão voluntária dos empregadores; destes, apenas 10\% haviam aderido ao "Programa" em $2016^{17}$. A instalação de salas exclusivas dentro do ambiente de trabalho para o aleitamento também se configura como alternativa para assegurar a prática ${ }^{18}$.

O avanço nas discussões sobre a temática do AM estimulou a transformação das rotinas de trabalho em serviços de saúde, sobretudo no âmbito das maternidades. Nessa perspectiva, a OMS, aliada à UNICEF, lançou a "Declaração Conjunta Sobre o Papel dos Serviços de Saúde e Maternidades", onde se apontaram 10 ações de incentivo à prática do aleitamento, conhecidos como os "10 passos para o sucesso do AM"10.

Após conferência internacional promovida por autoridades de saúde, foi aprovada por representantes de entidades públicas e civis, bem como de agências das Nações Unidas, a "Declaração de Innocenti", cujo propósito foi de estabelecer metas e objetivos para garantir o AME até os 04-06 meses de vida, complementado com alimentos saudáveis até os 02 anos ou mais, num prazo de cinco anos. Para isso, o documento elencou quatro ações: 1) formar uma coordenação e um comitê pró-amamentação; 2) assegurar o cumprimento dos "10 passos" pelas maternidades; 3 ) implementar por completo o "Código Internacional" instituído em 1979 e as subsequentes resoluções aprovadas pela Assembleia da OMS; e 4) garantir à mulher trabalhadora o direito de amamentar e estabelecer meios adequados para isto?.

Tendo como objetivo incentivar o cumprimento dos "10 passos", desde o período pré-natal até após o parto, foi desenvolvido o programa Iniciativa Hospital Amigo da Criança (IHAC), sendo o Brasil um dos pioneiros na adesão. Além daquela meta, para receber a certificação como "Amigo da Criança", a maternidade deveria atender a outros pré-requisitos, como praticar o AC, diminuir as taxas de cesáreas e respeitar o disposto na $\mathrm{Ncal}^{19}$. Neste cenário, o engajamento dos profissionais de saúde e demais funcionários mostrou-se fundamental para possibilitar a mudança dos processos de trabalho e do ambiente ${ }^{20}$.

Originado em Bogotá, na Colômbia, como alternativa à escassez de incubadora, o Método Canguru foi estabelecido no Brasil enquanto política pública denominada "Norma de Atenção Humanizada ao Recém-Nascido de Baixo Peso - Método Canguru”, ten- do como finalidade empreender alteraçóes na rotina de unidades neonatais de terapia intensiva e/ou de cuidados intermediários, como facilitar o contato com os pais, permitindo-lhes a entrada e permanência, bem como encorajar o contato pele a pele, estimular a amamentação e os cuidados com o bebê $\hat{~}^{10}$.

Desempenhando papel relevante na rede de apoio à gestante e à nutriz, o pilar da Atenção Primária em Saúde (APS) também é indispensável para a promoção, proteção e apoio ao AM. Deste modo, foram implantadas diversas ações de incentivo à prática, tendo como exemplos a "Iniciativa Unidade Básica Amiga da Amamentação", que objetivou fomentar os "10 passos" no âmbito da $A B$ por meio da capacitação profissional ${ }^{21,17}$; e a "Rede Amamenta Brasil", a qual provocou uma reformulação e a pactuação das ações no fluxo de atendimento interdisciplinar ao binômio mãe-filho ${ }^{3,17}$.

Instituída através da Portaria $\mathrm{n}^{\circ}$ 1.920/2013, a "Estratégia Amamenta e Alimenta Brasil (EAAB)" agregou as ações da "Rede Amamenta Brasil" e da "Estratégia Nacional de Promoção da Alimentação Complementar Saudável". Enquanto certificação no âmbito da APS, a EAAB trazia em seu escopo a qualificação das ações empreendidas tanto para a promoção, proteção e apoio ao AM quanto à alimentação complementar saudável para crianças menores de 02 anos $^{22}$. Entre os critérios estabelecidos, incluíam-se a elaboração de um plano de ação para incentivar o $\mathrm{AM}$ e a alimentação complementar (AC), bem como o monitoramento dos índices destas práticas ${ }^{10}$.

Com especial atenção às crianças na primeira infância pertencentes à uma condição de maior vulnerabilidade, instituiu-se, por meio da Portaria $n^{\circ}$ 1.130/2015, a "Política Nacional de Atenção Integral à Saúde da Criança (PNAISC)". Organizada em sete eixos de ação, a diretriz tinha como principal meta a redução da morbimortalidade infantil por meio da atenção e cuidados integrais e integrados, desde a gestação até os 09 meses de vida. Desta maneira, contemplou o AM e a alimentação complementar saudável como condutas importantes a serem cumpridas ${ }^{3}$.

Mais um instrumento de âmbito nacional, o "Marco Legal da Primeira Infância" 
estabeleceu princípios e diretrizes norteadores para a criação de políticas públicas e/ou iniciativas correlatas em favor do desenvolvimento integral e saudável de crianças desde o nascimento até 0 06 anos de idade ${ }^{23}$. $\mathrm{O}$ dispositivo aborda a prática do $\mathrm{AM}$ enquanto orientação obrigatória às gestantes e familiares. Outro benefício amparado pela legislação foi o aumento, de cinco para quinze dias, do período da licença-paternidade aos que estivessem empregados em empresas "cidadãs"3.

\section{CONCLUSÃO}

Impulsionados pela preocupação com as altas taxas de mortalidade infantil em todo o mundo, diversos movimentos internacionais e nacionais em prol do AM foram empreendidos a fim de transformar a realidade, marcada também pela intensa atuação dos fabricantes de substitutos do leite materno, os quais eram fortemente recomendados.

Nesse âmbito de engajamento global, o MS normatizou diversas ações de promoção, proteção e apoio à prática. Como resultado, diversas pesquisas nacionais na área da saúde apontaram para uma tendência crescente do AME e do AM de forma continuada, o que contribui para o alcance das recomendações da OMS.

Por fim, é importante mencionar que a sucessão de iniciativas demonstra a pujança do tema e o interesse governamental de apoio ao AM, em consonância com as evidências epidemiológicas acerca dos seus benefícios.

\section{REFERÊNCIAS}

1. Lopes WC, Marques FKS, Oliveira CF, Rodrigues JA, Silveira MF, Caldeira AP et al Alimentação de crianças nos primeiros dois anos de vida. Rev paul pediatr. 2018;36(2):164-170.

2. Brasil. Ministério da Saúde. Secretaria de Atenção Primária à Saúde. Departamento de Atenção Básica. Saúde da Criança: Aleitamento Materno e Alimentação Complementar. Cadernos de Atenção Básica, n. 23, 2ª ed. Brasília: Ministério da Saúde; 2015.

3. Brasil. Ministério da Saúde. Secretaria de Atenção à Saúde. Departamento de Ações Programáticas Estratégicas. Bases para a discussão da Política Nacional de Promoção, Proteção e Apoio ao Aleitamento Materno. Brasilia: Ministério da Saúde; 2017. 68 p.

4. Walters DD, Phan LTH, Mathisen R. The cost of not breastfeeding: global results from a new tool. Health Policy and Planning. 2019;34(6):407-417.

5. Boccolini CS, Boccolini PMM, Monteiro FR, Venancio SI, Giugliani ERJ. Tendência de indicadores do aleitamento materno no Brasil em três décadas. Rev Saúde Pública. 2017;51(108):1-9.

6. Bauer DFV, Ferrari RAP, Cardelli AAM, Higarashi IH. Orientação profissional e aleitamento materno exclusivo: um estudo de coorte. Cogitare enferm. [Internet]. 2019 [cited 2020 Jul 11]; 24. Available from: http://dx.doi.org/10.5380/ce.v24i0.56532. 7. Santos EM et al. Avaliação do aleitamento materno em crianças até dois anos assistidas na atenção básica do Recife, Pernambuco, Brasil. Ciên Saúde Colet. 2019;24(3):1211-1222.

8. Mendes KDS, Silveira RCCP, Galvão CM. Revisão integrativa: método de pesquisa para a incorporação de evidências na saúde e na enfermagem. Texto \& Contexto Enferm. 2008;17(4):758-64.

9. Rea MF. Reflexões sobre a amamentação no Brasil: de como passamos a 10 meses de duração. Cad Saúde Pública. 2003;19(supl.1):37-45.

10. Hernandez AR, Víctora CG. Biopolíticas do aleitamento materno: uma análise dos movimentos global e local e suas articulações com os discursos do desenvolvimento social. Cad Saúde Pública. 2018;34(9):e00155117

11. Ungerer RLS, Miranda ATC. História do alojamento conjunto. J Pediatr. 1999;75(1):1-10.

12. Coca KP, Pinto VL, Westphal F, Mania PNA, Abrão ACFV. Conjunto de medidas para o incentivo do aleitamento materno exclusivo intra-hospitalar: evidências de revisões sistemáticas. Rev Paul Pediatr.
2018;36(2):214-220.

13. Oliveira MMB, Silva IA. Representações sociais de doadoras sobre a doação de leite humano em um hospital universitário. Ciência, Cuidado e Saúde [internet]. 2020 [cited 2020 ago 29];19. Available from: https://doi.org/10.4025/cienccuidsaude.v19i0.47104.

14. Passos LS, Kroll c, Borges I, Rocha EDM, Schultz LF. Acompanhamento dos atendimentos de puérperas e recém-nascidos em um Banco de Leite Humano. Esc Anna Nery. 2020;24(2):e20190089.

15. Silva KB, Oliveira MIC, Boccolini CS, Sally EOF. Promoção comercial ilegal de produtos que competem com o aleitamento materno. Rev Saúde Pública. 2020;54(10):1-10.

16. Prado ISCF, Rinaldi AEM. Compliance of infant formula promotion on websites of Brazilian manufacturers and drugstores. Rev Saúde Pública. 2020;54(12):1-10.

17. Rimes KA, Oliveira MIC, Boccolini CS. Licença-maternidade e aleitamento materno exclusivo. Rev Saúde Pública. 2019;53(10):1-12.

18. Ortelan N, Venâncio SI, Benício MHA. Determinantes do aleitamento materno exclusivo em lactentes menores de seis meses nascidos com baixo peso. Cad Saúde Pública. 2019;35(8):e00124618.

19. Lamounier JA, Chaves RG, Rego MAS, Bouzada MCF. Iniciativa Hospital Amigo da Criança: 25 anos de experiência no Brasil. Rev Paul Pediatr. 2019;37(4):486-493.

20. Silva CM, Pellegrinelli ALR, Pereira SCL, Passos IR, Santos LC. Práticas educativas segundo os "Dez passos para o sucesso do aleitamento materno" em um Banco de Leite Humano. Ciên Saúde Colet. 2017;22(5):1661-1671.

21. Pedraza DF. Duração do aleitamento materno e sua associação com características maternas e orientações sobre incentivo à amamentação recebidas no pré-natal em unidades básicas de Saúde da Familia de um município do Nordeste Brasileiro. Demetra (Rio J.). 2019;14(supl.1):e43189.

22. Venâncio SI et al. Associação entre o grau de implantação da Rede Amamenta Brasil e indicadores de amamentação. Cad Saúde Pública. 2016;32(3):e00010315.

23. Venâncio SI. Why invest in early childhood? Rev. Latino-Am. Enfermagem. [Internet]. 2020 [cited 2020 Ago 19];28:e3253. Available from: http://dx.doi.org/10.1590/1518-8345.0000-3253. 